\title{
Narcisismo e desamparo: algumas considerações sobre as relações interpessoais na atualidade
}

\author{
Caroline Garpelli Barbosa \\ Erico Bruno Viana Campos* (ㄱ) \\ Carmen Maria Bueno Neme
}

Universidade Estadual Paulista, Bauru, SP, Brasil

\begin{abstract}
Resumo: Este ensaio objetiva problematizar o fenômeno do narcisismo na atualidade, partindo da hipótese de que as relações interpessoais se configuram pelo desamparo em sua dimensão traumática, e não como abertura à alteridade. Isso se daria assim porque, no atual cenário social, as relações humanas tendem a não oferecer apoio e suporte alteritário para a transformação e o desenvolvimento do sujeito, pois o coloca diante de três ameaças desagregadoras: o vazio solitário, a invasão do outro e a impotência. Na ausência de relações de amparo, o outro aparece como ameaça diante da qual o narcisismo advém como possibilidade de defesa e prevalece em sua forma de narcisismo regenerador.
\end{abstract}

Palavras-chave: narcisismo, desamparo, relações interpessoais, psicanálise.

Freud (1917/2010), ao afirmar que "o Eu não é senhor em sua própria casa" (p. 250), encontrou resistências de todos os lados por ferir a ilusão narcísica da humanidade ocidental e moderna de sujeito da consciência. Estava posta, em tal afirmação, a dificuldade em lidar com a dimensão alteritária e tudo o que rompe com a estabilidade instituída, escapa ao controle e chega de modo imprevisível, em toda sua potência ameaçadora de indeterminação, revelando a estrutura precária e frágil de nossa subjetividade.

O que dizer, então, da condição do indivíduo contemporâneo, que em meio às suas atividades se vê constantemente às voltas com notícias de catástrofes naturais, violência, assassinatos, terrorismos? A ameaça parece estar por todos os lados e, assim, assume muitas vezes um caráter indeterminado: está em toda parte e, ao mesmo tempo, nem sempre é possível tocá-la. Isso significa que a vulnerabilidade da condição humana se anuncia a cada esquina, a cada nova notícia de tragédia, levando à sensação de perda da confiabilidade e, por conseguinte, a um estado angustiante de que algo ruim pode ocorrer a qualquer momento. Em uma sociedade em que se é levado a ver o outro como concorrente, rival ou inimigo a ser combatido, confiar tornou-se quase uma tarefa heroica. No mais das vezes, contudo, a regra a ser seguida diante das relações humanas é a do afastamento defensivo ou assunção de comportamentos hostis.

Como exemplo de como isso se dá em nosso país, Dunker (2015) apresenta a lógica do condomínio, que subjaz ao ideal de consumo da classe média:

*Endereço para correspondência: erico.bv.campos@unesp.br o residencial fechado da vida entre muros, cujo objetivo é ocupar um espaço e delimitar um território, protegendo-o de possíveis intrusões. Não por acaso, o autor considera que os condomínios aparecem como uma tentativa de afastar ou mesmo abolir da esfera cotidiana tudo o que diz respeito à precariedade, riscos e incertezas: "uma região isolada do resto, onde se poderia livremente exercer a convivência e o sentido de comunidade entre iguais" (Dunker, 2015, p. 47).

Bauman $(1998,2004)$ também destaca a crise presente nas relações humanas na atualidade, as quais se tornaram uma das maiores fontes de ansiedade, pois, ao mesmo tempo em que se espera estreitar os vínculos, estes sempre acabam se mostrando frágeis e insuficientes para que sejam plenamente confiáveis. Psicanalistas (Birman, 2005, 2014; Costa, 1988, 2005) também têm se atentado à atualidade como uma época marcada pelo predomínio da imagem, pela velocidade e intensidade de acontecimentos, excesso e simultaneidade das informações, da fragmentação das unidades em prol das multiplicidades e variedades, na qual a solidez e durabilidade dos relacionamentos, dos projetos e do próprio mundo se enfraqueceram. Como consequência dos novos processos de subjetivação ocorridos nesse cenário, as temáticas do desamparo e do narcisismo têm sido recorrentes no campo de estudos da psicanálise, sendo apresentadas em conexão com as experiências de pânico, depressão, violência, transtornos de imagem corporal, expressões do sentimento de que, cada vez mais, o sujeito está lançado em situações e afetos que ele não consegue simbolizar e tampouco antecipar (Campos, 2016; Garcia \& Coutinho, 2004; Menezes, 2005; Pereira, 2008). 
Um aspecto de destaque que se observa no modo como são tecidas as relações humanas na atualidade é a eliminação do outro enquanto figura de alteridade e a assunção de relações simétricas, nas quais ele é visto como um objeto a ser usado em prol do engrandecimento e da exaltação da própria imagem e que, tão logo não seja mais útil nessa função, pode facilmente ser descartado e substituído. É nesse sentido que se costuma dizer que as subjetividades de hoje são, em grande medida, narcísicas, isto é, subjetividades autocentradas, porém exteriorizadas, uma vez que buscam a si mesmas no olhar admirado que o outro pode ter diante de sua imagem, performance e desempenho (Birman, 2005). Nessa mesma direção, Costa (2005) descreve a atualidade como cultura somática, na qual a identidade dos sujeitos passou a ser definida a partir dos atributos físicos do corpo, de modo que até mesmo o prazer e o ideal de felicidade estão circunscritos ao corpo e àquilo que ele pode proporcionar, seja por meio da satisfação sensorial, seja pelo interesse e curiosidade que manifesta nos outros. É nesse sentido que a forma do corpo e seu desempenho se transformaram também em garantia de admiração moral, de tal forma que aqueles que não cultivam o ideal de ter uma boa qualidade de vida, não cuidam do corpo, da saúde e da beleza, são considerados fracos, negligentes e incompetentes. Assim, uma das consequências da cultura somática e performática é a relação ambígua e contraditória que passa a haver nas relações interpessoais. Isso porque, se por um lado os outros são necessários para a confirmação da imagem que cada um possui de si, por outro, eles se apresentam como ameaça indesejável por revelarem não só quão distante do ideal este sujeito se encontra, mas também sua vulnerabilidade ao sustentar a própria identidade em uma imagem.

Do ponto de vista psicanalítico, esse sentimento de vulnerabilidade, contudo, encontra seu fundamento na própria constituição do Eu, uma vez que este nada mais é que um precipitado de imagens e vivências que se constitui na relação com o outro e que, embora conquiste certa unidade ao longo de seu desenvolvimento, sempre resguarda, em seu modo de estruturação, uma fragilidade de suas fronteiras (Freud, 1914/2010). Essa visão, que retira o aparelho psíquico de um modelo que até então parecia assentado em um processo desenvolvimentista e endógeno para assentá-lo em um modelo intersubjetivo, embora ganhe força com a introdução do conceito de narcisismo pela teoria psicanalítica, recebe destaque nas discussões atuais feitas em torno da problemática do desamparo, uma vez que este é entendido como a condição fundamental para que se deem os laços sociais e, por conseguinte, a constituição do Eu (Birman, 2014; Menezes, 2012). Ocorre que o desamparo, além de se configurar como abertura ao outro, também pode ser sentido como ameaça, mobilizando processos defensivos, entre os quais se inclui o próprio o narcisismo. Isso porque, além de um narcisismo primário e constitutivo do $\mathrm{Eu}$, há também condições regressivas do narcisismo dentro do amplo escopo do que Freud (1914/2010) denominou de narcisismo secundário, mas que ganhou desdobramentos importantes, como a ideia de um narcisismo negativo ou de morte (Green, 1988). Nesse sentido renovado, o narcisismo pode ser entendido como um processo primário de elaboração psíquica diante do traumatismo ao qual o aparelho psíquico se vê exposto desde o início de sua estruturação (Campos, 2014).

Diante desse contexto, este ensaio tem como objetivo discutir e problematizar o fenômeno do narcisismo presente nas relações humanas da atualidade a partir do referencial teórico da psicanálise, mediante a articulação com o conceito de desamparo. Nossa hipótese é de que a prevalência de relações interpessoais narcísicas, caracterizadas por um autocentramento exteriorizado, em que o outro comparece como objeto que suporta e confirma a fantasia identitária de uma pessoa enquanto ao mesmo tempo ameaça essa mesma identidade, traz a marca do desamparo em sua dimensão traumática, e não em sua dimensão criativa.

\section{A noção freudiana de desamparo}

Inicialmente, Freud (1895/1995) apresenta o desamparo em articulação com a incapacidade motora e biológica do bebê em satisfazer suas próprias necessidades vitais. Para o autor, é esta incapacidade que faz que o bebê se encontre numa posição de completa dependência do outro para acabar com sua excitação afetiva e, também, para instaurar nele a possibilidade do desejo. Tal dependência, contudo, vai muito além de um simples fato biológico. Ela se apresenta como condição de possibilidade para os laços sociais e para a inscrição do desejo no psiquismo da criança, o qual sempre implica um apelo ao outro, a fim de que este confira sentido ao seu desamparo (Fuks, 2003; Menezes, 2012).

Embora a concepção de desamparo apresentada no início não dê conta de acompanhar o alcance de seu pensamento tardio, ela percorrerá toda a obra do autor, ganhando força e ressonância em teorizações mais maduras e aparecendo com mais clareza quando Freud (1926/2014) apresenta o desamparo do recém-nascido como a experiência originária que está no fundamento de todas as situações de perigo geradoras de angústia. Isso porque, ao nascer, o bebê é tomado por uma onda de forte fluxo de excitação que o atinge de modo desenfreado e invasivo, lançando-o em um estado de total passividade e impotência porquanto ainda não há a possibilidade, inclusive biológica, de se defender. Ele não sabe se uma situação é ou não perigosa, uma vez que nele não há qualquer conteúdo psíquico ao qual a vivência inicial poderia se ligar, de modo que tudo o que lhe acontece ainda não tem nome, não é simbolizado e, portanto, não encontra lugar de representação. Há tão somente a sensação de ser atingido por uma grande quantidade de excitação, que produz uma forte sensação de desprazer e é associada a uma modalidade de angústia originária, 
a saber, a angústia automática (Freud, 1926/2014). Como o bebê humano nasce menos pronto que os demais animais, os perigos do mundo externo lhe aparecem com mais ênfase e força, o que faz o objeto capaz de protegê-lo desses perigos ter um valor muito grande e instaurar, por toda a vida do ser humano, sua forte necessidade de ser amado e sua dependência de seu objeto de amor. Como é a mãe que geralmente satisfaz as necessidades do bebê, sua ausência se configura como uma situação de perigo, posto que, sem ela ali para auxiliá-lo, a sensação de desprazer é elevada a magnitudes muito intensas, análoga à que se dá no momento do nascimento.

Apesar de colocar as duas situações como constituídas pelo mesmo núcleo de perigo, Freud (1926/2014) estabelece uma diferenciação entre ambas. O que ocorre na experiência do nascimento é a angústia automática, uma perturbação econômica involuntária, que se encontra na origem de todo o funcionamento psíquico e no núcleo de todas as experiências de perigo. Já a angústia pela ausência da mãe é de natureza defensiva e tem função de proteção, pois é emitida deliberadamente pelo Eu sempre que uma situação análoga à do nascimento possa ocorrer. Esta última é chamada de angústia-sinal. Desse modo, enquanto a criança não conseguir dominar a angústia automática e emitir um sinal de angústia para poder se defender, ela continuará sendo acometida pela descarga brutal da angústia automática e sentirá que está completamente impotente e desamparada para sair daquela situação.

O domínio da angústia automática passa diretamente pela emergência de um $\mathrm{Eu}$, pois é somente a partir do momento em que ele se constitui como uma unidade que a emissão do sinal é viabilizada. Para que isso aconteça, a criança precisa ser investida afetivamente por um outro que a ampare e a introduza na lógica desejante, de forma que somente quando essa angústia for ligada e investida em representações esse desamparo poderá ser elaborado. Em contrapartida, se por um lado os adultos se apresentam como essa possibilidade das primeiras ligações pulsionais, por outro, eles também são uma presença estranha, excessiva e ameaçadora, posto que se impõe à criança como algo que escapa e está além de sua capacidade de simbolização no momento em que sua estruturação psíquica é ainda incipiente, configurando o que alguns autores denominaram de complexo do próximo (Fuks, 2003; Schneider, 1997).

Com isso, pode-se afirmar que, se o antídoto para o desamparo e para a experiência de aniquilação do aparelho psíquico é a presença cuidadosa que une, liga, nutre, enlaça e abriga, não é fortuita a afirmação de que "nunca estamos mais desprotegidos ante o sofrimento do que quando amamos, nunca mais desamparadamente infelizes do que quando perdemos o objeto amado ou seu amor" (Freud, 1930/2010, p. 39). É por sentir essa condição como ameaça que o sujeito é impulsionado a fugir em busca de proteção de amparo, o que pode levá-lo ou à busca de uma proteção absoluta, ou a uma construção criativa para poder lidar com sua condição. No primeiro caso, descobrem-se modalidades subjetivas altamente restritivas, para as quais o trabalho de elaboração psíquica encontra dificuldade para fluir, haja vista sua necessidade incessante de se defender da angústia (Birman, 2014; Menezes, 2012; Rocha, 1999).

Como exemplo, temos os casos em que prevalece a alienação de si a um outro, relações de servidão e dependência, bem como a procura por obtenção de prazer e refúgio no próprio corpo e em sua imagem (Figueiredo \& Coelho Junior, 2018). São diferentes, portanto, das saídas criativas diante do desamparo, capazes de ter nele a mola propulsora para um funcionamento psíquico mais livre, que não tenho como recurso quase exclusivo os processos defensivos.

O desamparo, portanto, marca um modelo de subjetividade aberta, que traz em si a marca do outro enquanto figura de alteridade e que, ao mesmo tempo, é condição fundamental de possibilidade para os processos defensivos e, também, para a transformação de vivências inomináveis para o campo da representação simbólica. Por isso essa abertura aos vínculos sociais possibilitada pelo desamparo não é isenta de contradições e conflitos, uma vez que, ao mesmo tempo em que o outro é presente na economia psíquica de qualquer sujeito, as relações humanas são marcadas pela vulnerabilidade inerente a essa estrutura de vinculação, pois, diante do outro, nunca há garantias de que ele responderá ao apelo que lhe é endereçado e tampouco se tem a certeza de como será sua resposta:

Difícil imaginar uma forma de solidão maior e mais dolorosa do que aquela do desamparado. . . . O desamparado sente-se tão só, como o náufrago perdido na imensidão do mar. A metáfora é uma tentativa de mostrar que a essência do desamparo é a solidão e o sentimento de impotência, constituídos pela impossibilidade do sujeito de encontrar sozinho uma saída para a situação em que se encontra. Mas ela não termina aí, porque, ao mesmo tempo e normalmente, o desamparo abre para a alteridade. Ele é um grito desesperado de ajuda lançado na direção do outro. Quando o grito fica sem resposta, o desamparo torna-se desespero. (Rocha, 2000, p. 343)

O que aqui se chama de desespero parece encontrar correspondência no que Birman (2014) chama de desalento e Campos (2014) entende por dor psíquica, vivenciada sempre que a experiência traumática de desamparo se efetiva. O interessante a ser observado nas considerações desses autores é a afirmação de que, no desenvolvimento do psiquismo, a dor tanto pode ser reação à perda de um objeto de amor como também registro de uma vivência inominável, que deixa uma marca indelével no funcionamento psíquico. Circunscreve então um espaço que resguarda a marca da possibilidade de aniquilação e de mergulho no abismo da radical indeterminação e, 
portanto, está além daquilo que pode ser representado pela angústia-sinal defensiva. Nesse sentido, por mais que se procure a todo custo se proteger dessa dor e da marca deixada por ela, a defesa nunca será absoluta.

Em linha de argumentação diferente, Costa (2007) apresenta uma visão mais esperançosa em relação ao desamparo humano. Partindo de uma visão pragmática, ele questiona a colocação do desamparo como categoria constitutiva na formação da subjetividade, por entender que a ênfase dada ao desamparo, em uma concepção freudiana, centraliza a discussão em torno da impotência humana e de sua impossibilidade em lidar com aquilo que o ultrapassa. Assim, apoiado em Žižek e, sobretudo, em Winnicott, o autor afirma que as experiências de falta ou vazio não costumam ser sentidas como desamparo, mas, sim, como lugar para a potência criadora, a qual possibilita que o sujeito possa inventar e criar a si mesmo, o mundo e, assim, sentir que a vida vale a pena ser vivida. Por isso, apenas quando o ambiente, entendido numa visão winnicottiana, não oferece as condições necessárias para que a criança sinta-se capaz de criar, é que se tem uma vivência semelhante àquela de desamparo traumático, a saber, as chamadas agonias impensáveis (Winnicott, 1974/1989). Isso quer dizer que, se o bebê, desde o início da sua vida, encontrou espaço para ser e experimentou a vida como criação, ele será também capaz de aceitar o que lhe acontece sem terror ou sem sentir que aquilo pode aniquilá-lo.

$\mathrm{O}$ que vale destacar neste momento sobre o desamparo é que ele oferece a possibilidade de pensar a estruturação do sujeito a partir de uma relação de abertura à alteridade que vem do outro e de si mesmo. Essa abertura, por sua vez, é o que faz que a vida esteja sempre em risco, sob iminência de constante desabamento, condição que pode ser vivida como trauma, desespero e desalento, e, por isso, mobilizar uma sensação de impotência e dor diante da qual o sujeito precisa se proteger ou fugir a qualquer custo. Por outro lado, essa mesma condição pode ser experienciada como possibilidade de abertura para a mobilização criativa do próprio existir. Assim, há indicações de que o caminho para uma ou outra dessas duas experiências passe, entre outros fatores, pelo modo como se configuram as relações com os outros e, em particular, como se dá este apelo a ele endereçado e, por conseguinte, a forma como acontece a correspondência a tal apelo, o que, do ponto de visa psicanalítico, implica o narcisismo.

\section{Um Narciso ferido em busca de si mesmo}

O mito de Narciso sempre é lembrado quando queremos nos referir ao amor que alguém sente por si mesmo. Nele, o apaixonamento pela própria imagem na água é tão intenso que o sujeito se torna incapaz de abandoná-la ou ver qualquer outra coisa ao seu redor. Preso à própria imagem, ao final, ele definha e morre sozinho, em uma cena que claramente nos faz lembrar a clássica afirmação de que "Um forte egoísmo protege contra o adoecimento, mas afinal é preciso começar a amar, para não adoecer, e é inevitável adoecer, quando, devido à frustração, não se pode amar" (Freud, 1914/2010, p. 29).

Freud (1914/2010) apresenta o narcisismo primário como parte do processo natural de desenvolvimento do psiquismo e, mais especificamente, como uma nova ação psíquica a partir da qual o Eu se desenvolve. Dessa discussão inicial, destacaremos a colocação do narcisismo como um momento fundamental na constituição do Eu, seu papel da formação dos ideais e, por fim, sua função de autoconservação e de defesa. No percurso de desenvolvimento infantil, o narcisismo primário se situa logo após a fase de autoerotismo e antes da fase de investimento em objetos, caracterizado como momento de investimento e confluência da pulsão sexual no Eu e, também, por certa organização da dinâmica pulsional, que é essencial para a sobrevivência e estruturação da sua unidade. Além disso, embora o ponto crucial trazido pelo conceito seja a formulação de que o Eu é tomado como objeto de investimento da pulsão sexual, cabe destacar a apresentação do narcisismo primário como condição de possibilidade para emergência das relações objetais. Assim, quando o investimento em si mesmo atingir um limiar excedente à capacidade de contenção do aparelho psíquico, o Eu passa a investir em objetos. No entanto, mesmo com o investimento em objetos, Freud (1914/2010) considera que o narcisismo infantil nunca é completamente abandonado. Na verdade, ele é deslocado para as instâncias ideais do Eu, que passam a substituí-lo e, assim, garantir que satisfações narcísicas ainda encontrem lugar.

O papel dos ideais na estruturação psíquica, contudo, apenas ficará claro e ganhará força ao final da obra freudiana, fato que, de acordo com Campos (2014), trará à tona alguns impasses para as discussões realizadas sobre o narcisismo. A principal delas diz respeito à problemática dos processos de identificação no âmbito da constituição do Eu, trazido à tona mediante a constituição do Super-eu na resolução do Complexo de Édipo e, portanto, das relações de identificação estabelecidas pelo Eu com os objetos. Ocorre que, embora a compreensão do aparelho psíquico pelos processos de identificação abra espaço para uma perspectiva mais relacional no interior da psicanálise freudiana, a ênfase conferida às identificações paternas no processo de estruturação da subjetividade leva a uma subvalorização do papel das identificações primárias narcísicas na constituição do Eu. Isso porque, se o narcisismo primário for apenas considerado como um estado anterior às relações objetais, isso significa que o bebê humano seria, de início, fechado às relações com os outros, algo que Freud nunca afirmou, uma vez que é a partir do investimento afetivo da figura de cuidado na criança que se dá a constituição subjetiva.

Uma das hipóteses para tal contradição e ambiguidade pode ser decorrente do silenciamento em relação ao papel da dinâmica da pulsão de morte na 
constituição do Eu e do apagamento das discussões sobre o processo de identificação nos períodos pré-objetais (Campos, 2014). Esse aspecto vale ser analisado com cuidado, pois é nele que se insere a discussão sobre a função defensiva exercida pelo narcisismo, que pode ser entendida como um processo primário de elaboração psíquica diante do traumatismo gerado pelo excesso pulsional disruptivo da pulsão de morte (Freud, 1920/2010). É nesse sentido que a organização narcísica tem uma função vital para a sobrevivência do psiquismo, na medida em que ela seria um trabalho de ligação e representação das energias originariamente desligadas. Pode-se afirmar que esse trabalho de ligação corresponde ao trabalho de Eros, pois cabe à pulsão de vida criar uma relação de investimento objetal, uma vez que, sendo a pulsão de morte mais originária que a pulsão de vida, essa ligação não está dada de início e depende da relação com o outro para desenvolver destinos até então inexistentes. Essa estruturação narcísica corresponde a um narcisismo que se dá mediante a incorporação dos objetos de amor e leva a um sentimento de unidade que possibilita ao sujeito seguir investindo em objetos e, também, em si mesmo.

Conferindo destaque ao papel da pulsão de morte na estruturação da subjetividade, Green (1988) amplia a teoria freudiana do narcisismo, apresentando o conceito narcisismo de morte, uma modalidade de narcisismo defensivo que, por caminhar na direção dos desligamentos e retração nos processos de identificação, e ser marcado pelo desinvestimento objetal característico da dinâmica da pulsão de morte, leva ao desenvolvimento de um Eu frágil em sua estruturação, com dificuldade de simbolização e marcado pelo sentimento de perda da identidade, de desagregação e, principalmente, de vazio. Tal quadro é apresentado pelo autor a partir da concepção da mãe morta, uma figura materna que, por algum motivo, não está viva o suficiente na relação com a criança, isto é, ela lhe confere os cuidados básicos, como alimentação, vestimentas etc., contudo não a investe afetivamente (Green, 1988). O Eu da criança, sentindo-se impotente diante da mãe morta, procurará formas de se defender, desinvestindo, ele também, do objeto materno e passando a se identificar com o buraco vazio e irrepresentável deixado pela ausência do seu amor. Nesse sentido, pode-se afirmar que o narcisismo de morte é um narcisismo ferido, marcado pela dor psíquica decorrente da falta de investimento psíquico.

Se articularmos essa proposição ao que foi anteriormente discutido, é possível avançar em direção a um questionamento acerca da qualidade dos vínculos, para que estes se configurem como um laço seguro, e não sobre o vazio. Isso porque a mãe morta ampara a criança no que tange às suas necessidades biológicas, contudo este amparo não é suficiente para dar continência à dinâmica pulsional mortífera e, assim, auxiliar em sua modulação e simbolização, o que faz que a identificação se dê pela via do negativo. Ou seja, sem receber o investimento suficiente que lhe oferece a sensação de segurança, desenvolve-se um Eu que, além de não investir nos objetos, apenas encontra o vazio e a morte dentro de si.

Costa (1988) retoma a posição freudiana de que o corpo é investido narcisicamente por ser causa de dor, e não por ser fonte de prazer, para diferenciar entre o que seria uma dor elaborada de acordo com o princípio do prazer - portanto de ordem secundária - e uma dor primária de potencial traumático. De acordo com ele, a primeira só pode acontecer depois que o evento traumático já foi simbolizado, isto é, quando ele já recebeu um sentido e foi investido libidinalmente, o que resulta em descarga pulsional e conseguinte cessação do desprazer. Em suma, temos que "o movimento psíquico é acionado pelo princípio do prazer-desprazer, que visa a descarga pulsional, e pela experiência de satisfação, que modela a busca do objeto perdido" (Costa, 1988, p. 226). Já a dor enquanto trauma tem um tipo de elaboração diferente, pois ela se relaciona com uma ameaça real de morte, em situações nas quais o psiquismo é pego de modo inesperado, portanto encontra-se despreparado para o ocorrido. Desse modo, pode-se dizer que a dor enquanto trauma surge como ameaça por remeter à possibilidade de uma experiência de aniquilação ou desintegração do $\mathrm{Eu}$, a qual o autor chama de violência:

Violência, a nosso ver, é toda ação traumática que conduz o psiquismo ou a desestruturar-se completamente ou a responder ao trauma através de mecanismos de defesa, análogos à economia da dor. Violenta é toda circunstância de vida em que o sujeito é colocado na posição de não poder obter prazer ou de só buscá-lo como defesa contra o medo da morte. (Costa, 1988, p. 228)

Nesse sentido, o autor define como narcisismo regenerador o investimento no corpo decorrente de uma tentativa do $\mathrm{Eu}$ em controlar a dor do trauma gerado pelas situações de violência. O que interessa a nossa discussão é a caracterização do narcisismo regenerador como a configuração principal do narcisismo contemporâneo, que é, portanto, defensivo, uma vez que faz o investimento no próprio $\mathrm{Eu}$ acontecer de modo a resguardar sua sobrevivência diante de ameaças advindas com a violência imposta pelo modo de vida atual fundamentado na sociedade do consumo. Esse tipo de configuração do narcisismo vem se alinhar a outras de caráter defensivo e regressivo - como a de narcisismo negativo apresentada anteriormente - ganhando evidência na literatura psicanalítica como um operador conceitual importante para a compreensão dos aspectos destrutivos e mortíferos em jogo nas configurações psicopatológicas da subjetividade contemporânea (Bocchi \& Campos, 2018; Menezes, 2012; Pereira, 2008).

Isso quer dizer que, para esses autores, o narcisismo contemporâneo está muito longe de ser um gozo hedonista consigo mesmo. Ao contrário, seria resultado da dor de um indivíduo violentado o tempo 
todo pelos excessos e fragmentação das informações, que muitas vezes estão além da capacidade do psiquismo em elaborar tais experiências; pela veiculação de padrões de beleza e saúde ideais, cujo único fim é perpetuar a insatisfação que aprisiona os sujeitos em uma busca que nunca cessa, posto que o ideal é inatingível. Assim, essas posições vão em direção às indicações oferecidas por Freud (1924/2011) quando apresenta a melancolia como o quadro representativo das neuroses narcísicas. Ou seja, o melancólico seria aquele que, ao perder o objeto amoroso ideal, identificou-se com ele e, por conseguinte, sentiu que perdeu a si mesmo (Freud, 1917/2010). Como consequência, ele se sente incapaz de investir em novos objetos, desinteressando-se pelo mundo exterior e, ao mesmo tempo, tornando-se destrutivo consigo mesmo. Desse modo, o narcisismo melancólico não leva a um amor pelo próprio $\mathrm{Eu}$, mas, sim, a uma tentativa frequente de não se perder junto com o objeto amado.

No plano das discussões mais atuais sobre o narcisismo no âmbito da cultura, Birman $(2005,2014)$ discute o quanto o modo de subjetivação tem se caracterizado pela vivência de uma dor solipsista e, portanto, narcísica que, ao mesmo tempo em que precisa corresponder ao imperativo da performance, expondo-se e buscando admiração e confirmação de sua identidade, também se sente impotente para corresponder aos ideais de desempenho. Trata-se, nesse sentido, de um narcisismo autocentrado em sua dor, mas que, ao mesmo tempo, exterioriza-se em sua busca pelo outro. Essa busca, contudo, não corresponde a um apelo a este outro enquanto figura de ajuda ou de alteridade. A demanda é por sua permanência concreta como suporte para a própria imagem, o que, por sua vez, leva a uma experiência de alienação, na medida em que o sujeito não tem posse de quem é. Além disso, mesmo a identidade adquirida por meio do olhar do outro é sempre muito frágil e está sob constante ameaça de desabamento, o que leva o sujeito a um paradoxo difícil de ser transposto, pois, quanto mais se expõe para firmar sua identidade, mais depara com a possibilidade do terror de perder a si mesmo. Não por outro motivo, o autor entende que o outro pode aparecer como uma presença excessiva, estranha e ameaçadora, da qual o sujeito tenta se livrar a fim de não ter a própria imagem desconstruída.

Seguindo das indicações de Birman (2005) sobre as conexões entre masoquismo e pulsão de morte, Menezes (2012) discute, no plano da cultura, o quanto o terror experienciado pelo sujeito, decorrente da fragilidade de seus laços sociais, tem intensificado a emergência do masoquismo enquanto modalidade subjetiva central, na qual o que se busca nas relações com o outro é proteção diante do próprio desamparo. Assim, para não estar à mercê do curto-circuito da própria lógica pulsional aniquiladora, o sujeito se assujeita ao outro e ao desejo deste, mantendo-se em uma posição de servidão e submissão na qual impera a lógica da onipotência narcísica. Ou seja, para este tipo de estruturação subjetiva, qualquer coisa vale a pena, desde que o ideal narcísico não seja destruído ou ameaçado pelas dúvidas e incertezas advindas da abertura às diferenças.

Em síntese, pode-se afirmar, com base na literatura psicanalítica citada, que as configurações socioculturais do período histórico conhecido como pós-modernidade ou modernidade tardia tendem a fomentar modulações estruturais da subjetividade centradas em dinâmicas da ordem do masoquismo e do narcisismo. Isso demonstra como os esquemas metapsicológicos universais que balizam o campo psicanalítico se mostram pertinentes para compreender as modulações históricas e culturais da subjetividade humana e nos ajudam a ultrapassar as dicotomias simplistas e ainda modernas entre natureza e cultura ou universalidade e historicidade.

\section{O isolamento narcísico e o desamparo na atualidade}

Realizado este percurso, cabe voltar a nossa hipótese inicial de que grande parte do narcisismo identificado nos sujeitos da atualidade se configuraria pelo isolamento defensivo do sujeito, que acaba vendo o outro muito mais como ameaça do que propriamente como ajuda e amparo.

No início da discussão sobre o desamparo, ele foi apresentado como uma condição de abertura ao outro, portanto como condição para a estruturação do psiquismo. Isso porque, quando a criança é atingida pelo excesso de excitação em relação à qual ele não tem como lidar ou representar, um outro vem até ele e, ao protegê-lo e aliviá-lo, constrói sentido àquela experiência desprovida de significados. Pode-se dizer assim que é o outro que realiza o trabalho de ligação que o bebê é incapaz de realizar; é o outro, portanto, que permite que a força pulsional seja transformada e inserida em um circuito libidinal e ganhe representantes psíquicos (Birman, 1999; Campos, 2014; Costa, 1988; Green, 1988; Menezes, 2012). Nesse sentido, é nessa relação que o bebê pode, mediante identificações narcísicas, gradativamente, conferir destinos às suas experiências e, assim, constituir um Eu que lhe permita se defender do desamparo aniquilador. Nesse modelo de desenvolvimento psíquico se observa que a possibilidade de evitar a descarga traumática da pulsão de morte só é viável mediante a ação de um outro capaz de auxiliar na conjugação entre a força pulsional e a representação. Por essa razão, a relação com os outros é vital ao psiquismo, não apenas no início da vida, mas durante todo seu percurso, de tal forma que, "quando o encontro não acontece fica o desamparo como terror. O desamparo demanda continência, demanda uma construção a dois (bebê-mãe) na experiência, de modo que cada sujeito elabore os acontecimentos e altere a si mesmo" (Menezes, 2012, p. 111).

Ocorre que, como vimos, a atualidade está cada vez mais marcada por relações nas quais o outro aparece como ameaça, pois, se em sua ausência corre-se o risco 
de ser lançado à solidão e de não ter mais seu suporte identitário, sua presença pode ser excessiva e, ao mesmo tempo, destruir a imagem ideal creditada ao próprio $\mathrm{Eu}$. Se as coisas se dão desse modo, cabe uma reflexão sobre as formas de vinculação que estão sendo construídas em tal cenário, pois, diante das considerações apresentadas sobre o narcisismo, sobretudo o narcisismo defensivo, pode-se considerar que ele anda, a par e passo, com relações que não podem ser vividas como apoio e suporte alteritário para a transformação e desenvolvimento do Eu.

Como vimos, o mal-estar contemporâneo pode ser caracterizado como uma experiência de dor desalentada, "em que a subjetividade se fecha sobre si mesma, não existindo qualquer lugar para o outro no horizonte do seu mal-estar" (Birman, 2014, p. 140), uma vez que precisar do outro se transformou em sinônimo de fracasso e impotência, por ferir a ilusão narcísica. Por esse motivo, na dor, o sujeito aguarda passivamente que este outro compareça para ajudá-lo, sem nunca lhe endereçar sua demanda de amparo. Essa modalidade de mal-estar é oposta à experiência de sofrimento na qual reside uma abertura para o apelo ao outro em sua dimensão alteritária, que possibilita e viabiliza o movimento de elaboração psíquica. O sofrimento, portanto, seria da ordem do desamparo, pois pressupõe que o outro estará lá para oferecer suporte afetivo e auxiliar na produção de sentido. Se, por outro lado, este outro é o rival ou ameaça em potencial e não pode ser encontrado como referência, o sujeito se vê exposto e entregue a si mesmo, de modo que, sem esperança de conferir destino à sua dor e transformá-la, ele cai em desalento e padece em seu enclausuramento.

Ao retomar a afirmação de Dunker (2015) de que os muros dos condomínios são criados para evitar a entrada de tudo aquilo que remete à indeterminação, ao que é diferente e desconhecido, talvez não seja exagero afirmar, tecendo um paralelo com o desamparo traumático, que essa experiência reflete uma condição subjetiva psicossocial. Isso porque o autor apresenta o mal-estar na atualidade como uma experiência de angústia vaga e difusa, diante da qual, em primeiro lugar, o sujeito cerca-se entre iguais e busca se isolar para não ser atravessado pela indeterminação advinda com a diferença que presença do outro impõe e, em segundo lugar, tenta nomear seu mal-estar a qualquer preço, inserindo-o em uma estrutura narrativa de sofrimento que consiste em identificar quais seriam os agentes causadores do mal. Naturalmente, para esses discursos, o mal vem sempre de fora e com a estranheza advinda com o outro e seu modo de ser, sua crença, orientação sexual, raça, etnia etc., o que acaba por favorecer o surgimento do narcisismo das pequenas diferenças (Freud, 1921/2011).

Nos trabalhos de Birman (2014) e Dunker (2015), notam-se duas maneiras semelhantes de abordar a temática do desamparo e das relações com o outro, ainda que utilizem noções e conceitos diferentes. Ambos ressaltam a dimensão de fechamento e aprisionamento diante de um outro ameaçador, sendo que o que Dunker chama de malestar parece se aproximar do que Birman está denominando de dor. Em todo caso, o que está em discussão para ambos, no que diz respeito aos modos de subjetivação atuais, é a experiência de incapacidade em suportar a alteridade sem a sensação de ser aniquilado por ela.

Segundo Birman $(2005,2014)$, grande parte dessa impossibilidade decorre da própria dinâmica do mundo contemporâneo, o qual, marcado pela imprevisibilidade e instabilidade, tem intensificado as experiências de desamparo em seu sentido traumático, uma vez que lança o sujeito de modo cada vez mais recorrente em situações e afetos que ele não mais consegue simbolizar e, tampouco, antecipar. Nesse sentido, tendo em vista a divulgação dos inúmeros casos de violência cotidiana, tragédias, assassinatos, crueldade, o desamparo vivenciado diante do outro parece não encontrar mais seu correlato necessário, a saber, o amparo seguro e confiável, de sorte que, sem poder ver o outro como ajuda, resta ao sujeito a sensação de estar à deriva e na solidão, a bordo de um abandono que, em tais condições, apenas pode ser experienciado como dor. Ou seja, ainda que o desamparo seja tido como uma experiência de abertura ao outro, se o grito em direção ao outro não encontra seu correspondente ou, ainda, se este outro, quando vem, aparece mais como ameaça do que como auxílio com o qual se pode contar, o psiquismo é acometido pelo terror, ou seja, é inundado pelo desamparo traumático contra o qual precisará ocupar-se de se defender. Nesse sentido, o isolamento narcísico não deixa de ser um meio encontrado para se evitar a morte psíquica. Ao seguir a lógica de argumentação de Costa $(1988,2005)$, para quem o sujeito violentado lida com o objeto pelo modelo da dor, talvez seja possível afirmar que o outro esteja se apresentando como este elemento estranho e ameaçador.

O paradoxo em jogo nessa relação é que, ainda que o outro apareça como ameaça, o sujeito precisa constantemente se lançar na direção dele, a fim de inscrever em si as marcas dessa presença que nunca permanece enquanto figura internalizada. Assim, ao retomar as discussões apresentadas por Green (1988), é possível problematizar até que ponto este outro, quando não vem como ameaça, talvez se apresente apenas como um registro de ausência, ou nulidade, levando o Eu a construir-se constantemente sobre uma sensação de vazio. Isso porque, nas configurações subjetivas atuais, o que se busca no outro não é o outro, mas o mesmo, a própria imagem, tal como Narciso em frente ao lago. A imagem, contudo, não dá conta de oferecer ao sujeito o tamponamento seguro para o vazio que nele habita, haja vista que encontrar a própria identidade numa imagem é sempre arriscado, pois nessa forma de relação, o Eu sempre está sob posse do outro. Sem ser senhor da própria casa, ele permanece à deriva e despovoado, de sorte que, se o outro não é internalizado, resta apenas a busca compulsiva e incessante por sua presença concreta, 
sem nunca ter a garantia de que ele ali permanecerá, e sem a certeza de que o espelho encontrado não revele o estranho e indesejável de si mesmo. Se, como afirma Bauman (2004), as relações sociais se tornaram líquidas, resta saber o quanto, inclusive elas, têm o potencial de se construírem de modo sólido, duradouro e profundo, para além do mundo superficial e fugaz das imagens.

Um dos recursos apresentados diante de tal contexto é desaparecer do olhar do outro próximo e tentar obter o reconhecimento imaginário de figuras anônimas e distantes (Costa, 2005, 2007), Com isso, o ideal de felicidade fica circunscrito ao próprio corpo e, mais precisamente, às próprias sensações, pois é daí que sustentará o sentimento de que existe. Todavia esse tipo de satisfação imediata é fugaz e pobre em seu processo de simbolização, levando o sujeito a ter que vivê-la e reiniciá-la, a cada vez, em busca de novos objetos e sensações. Tal necessidade conduz a um excesso que, ao mesmo tempo, satisfaz momentaneamente e deixa o sujeito exposto e vulnerável às excitações que ele mesmo desconhece, do mesmo modo que o leva cada vez mais a relações marcadas pelo distanciamento e superficialidade, para as quais o outro pode se apresentar como objeto descartável, uma vez que sua presença é necessária até o momento em que confirma a imagem que o sujeito tem de si.

Diante do exposto, pode-se afirmar que o sujeito se vê constantemente diante de, ao menos, três ameaças desagregadoras, a saber: o vazio solitário vivenciado como desespero e desalento, a invasão do outro com sua presença excessiva e além da capacidade psíquica em representar, e, por fim, a impotência advinda com a incerteza revelada pelo que o olhar do outro reflete sobre a própria imagem e sobre a veracidade do vínculo entre eles existente. Os três casos confrontam o sujeito com sua experiência de desamparo radical, as quais, por requererem um processo de elaboração intenso e exaustivo, leva-o a estar sempre lutando para se proteger e, assim, regular o impacto dessas vivências no psiquismo, para que ele não entre em uma convulsão econômica e nem sucumba ao próprio vazio.

A questão que devemos problematizar neste ponto é se, de fato, as configurações atuais de laços sociais precisam ser tão fatalistas, de modo que ou bem o sujeito está aberto à alteridade, ou bem está aprisionado em sua grandiosidade narcísica. Como alternativa a tal polarização, Costa (2007) sugere que as coisas mudam de figura se onipotência e impotência, autonomia e heteronomia, em vez de serem tomados como polos separados em oposição, forem entendidos como faces de uma mesma moeda. Nesse sentido, a autossuficiência não precisaria significar apenas menosprezo ou alienação ao outro, como também não precisaria apenas ser uma experiência aterrorizante de solidão. Por isso sugere uma visão mais otimista para a qual assumir a condição de desamparo não seja simplesmente ir de braços abertos em direção aos acontecimentos trágicos da vida, em uma espécie de amor fati nietzschiano, tampouco seja entendido como uma forma onipotente e solitária de lidar com atribulações inerentes ao existir, que nada mais seria do que uma defesa de nossos ideais narcísicos regidos pela lógica utilitarista na qual não há espaço para experiências de falha. Ao contrário, a ilusão de onipotência é parte do processo de desenvolvimento, não porque seja uma defesa diante de irrupções pulsionais, mas porque manifesta a potência criativa inerente a todo e qualquer ser humano. Tal ilusão, por sua vez, depende de um ambiente que ofereça uma relação de cuidado e confiança, a partir da qual a criança manterá o sentimento de que continua existindo e, assim, sente-se livre para espontaneamente criar a si e ao seu mundo.

No interior dessa perspectiva, a relação com o outro não se apresenta a partir da falta ou do excesso, salvo quando estes impossibilitam à criança de seguir em seu senso de que continua a existir. O outro aparece, nesse sentido, muito mais como apoio para que a falta, inerente a todo ser humano, seja experienciada não como horror, mas como abertura e possibilidade para o movimento de transformação e desenvolvimento. É nesse sentido que Costa (2005), embora problematize a questão da cultura somática, com sua ênfase no cuidado do corpo, também a apresenta como uma possibilidade para o surgimento de outra relação com o corpo, que implique também numa preocupação ética consigo, capaz de oferecer ao indivíduo a opção por viver melhor e a encontrar, no próprio corpo, também a própria história. Certamente, tal forma de cuidado só é possível quando ele deixa de ser refém das imagens.

Com estas considerações, pode-se retomar nossa hipótese inicial de que o narcisismo, em sua versão contemporânea de autocentramento exteriorizado, pode ser considerado em estreita relação com o desamparo traumático enquanto experiência desagregadora do psiquismo, o que nos leva a refletir sobre a especificidade dos laços humanos construídos na atualidade, na medida em que estes não parecem suficientemente sólidos e confiáveis para se apresentarem como fonte de segurança em relação ao desenvolvimento criativo e à própria capacidade de se lançar ao outro com todos os riscos que isso implica. O âmbito das relações humanas não se constitui pela via da garantia em relação ao que será recebido e conquistado e, ao que se observa, ainda se está distante da aceitação corajosa de que é possível sobreviver, mesmo quando a ilusão narcísica de onipotência ameaça ruir.

\section{Considerações finais}

À guisa de conclusão, cabe uma breve reflexão acerca da dimensão ética da alteridade diante do cenário apresentado, pois abrir-se ao outro implica estar disposto e preparado para deixar cair por terra as ilusões de proteção absoluta, tal como "um filho que deixou a casa do pai, 
que era aquecida e confortável” (Freud, 1927/2014, p. 292). Isso significa, se não abandonar, ao menos estar disposto a suspender muitas das convicções totalizantes sobre si e sobre os outros, em favor de uma postura amigável a tudo que se apresenta estrangeiro, isto é, como aquilo que vem até nós, mas que é oriundo de outra terra, de outro lugar. Por outro lado, não se pode deixar de considerar que a coragem para encarar o desconhecido talvez seja mais forte e consistente, após um longo caminho trilhado em segurança, na presença e amparo de um outro capacitado e disposto ao cuidado vivo e genuíno. Do contrário, até mesmo a brisa leve e não pretensiosa pode ser vivida como o mais ameaçador dos furacões. Com isso, não é nosso intuito afirmar que as relações sociais da atualidade estão fadadas ao fracasso e só podem gerar experiências de dor. Antes, trata-se de ressaltar ainda mais a necessidade de olhar cuidadosamente para este campo, a fim de que, a partir do tensionamento promovido pela reflexão, possa emergir de seu próprio bojo saídas criativas, e não fruto da ilusão narcísica de onipotência, que tornem possíveis ações criativas e transformadoras para lidar com a realidade que se apresenta. Com isso, a psicanálise, com sua ética assentada no modelo alteritário de subjetividade, reitera sua força e importância na medida em que oferece ao sujeito a abertura em direção à qual ele pode endereçar sua demanda de cuidado a um outro que o refletirá para além do espelho ideal.

\section{Narcissism and helplessness: some considerations on interpersonal relations today}

Abstract: This essay aims to discuss the phenomenon of narcissism today based on the hypothesis that interpersonal relationships are shaped by helplessness in its traumatic dimension rather than by an opening to otherness. This is explained by the fact that, in the current social scenario, human relationships lack alteritary help and support for subjects' transformation and development, placing them towards three disaggregating threats: the solitary emptiness, the invasion of the other, and the impotence. Before the absence of relations of protection, the other appears as a threat against which the narcissism emerges as a defense mechanism, prevailing in the form of regenerating narcissism.

Keywords: narcissism, helplessness, interpersonal relations, psychoanalysis.

\section{Narcissisme et détresse : quelques considérations sur les relations interpersonnelles aujourd'hui}

Résumé : Cet essai problématise le phénomène du narcissisme aujourd'hui, en supposant que les relations interpersonnelles sont configurées par la détresse dans sa dimension traumatique et pas comme une ouverture à l'altérité. Cela se produirait parce que dans le scénario social actuel, les relations humaines tendent à ne pas offrir de soutien et de support d'altérité pour la transformation et le développement du sujet, en le plaçant devant trois menaces de désagrégation : le vide solitaire, l'invasion de l'autre et l'impuissance. En l'absence de relations de soutien, l'autre apparaît en tant qu'une menace devant laquelle le narcissisme surgit comme une possibilité de défense et prévaut dans sa forme de narcissisme régénérateur.

Mots-clés : narcissisme, détresse, relations interpersonnelles, psychanalyse.

\section{Narcisismo y desamparo: algunas consideraciones sobre las relaciones interpersonales en la actualidad}

Resumen: Este ensayo pretende problematizar el fenómeno del narcisismo en la actualidad partiendo de la hipótesis de que las relaciones interpersonales no se configuran por la apertura a la alteridad, sino por el desamparo en su dimensión traumática. Esto se debe a las relaciones humanas, que el escenario social actual tienden a no ofrecer ayuda y apoyo a la alteridad para la transformación y el desarrollo del sujeto, pues lo coloca ante tres amenazas desagregadoras: el vacío solitario, la invasión del otro y la impotencia. En la ausencia de relaciones de amparo, el otro aparece como amenaza ante la que el narcisismo adviene como posibilidad de defensa y prevalece en su forma de narcisismo regenerativo.

Palabras clave: narcisismo, desamparo, relaciones interpersonales, psicoanálisis.

\section{Referências}

Bauman, Z. (1998). O mal-estar da pós-modernidade. Rio de Janeiro, RJ: Zahar.
Bauman, Z. (2004). Amor líquido: sobre a fragilidade dos laços humanos. Rio de Janeiro, RJ: Zahar. 
Birman, J. (1999). A dádiva e o outro: sobre o conceito de desamparo no discurso freudiano. Physis: Revista de Saúde Coletiva, 9(2), 9-30.

Birman, J. (2005). Mal-estar na atualidade: a psicanálise e as novas formas de subjetivação (5a ed.). Rio de Janeiro, RJ: Civilização Brasileira.

Birman, J. (2014). O sujeito na contemporaneidade: espaço, dor e desalento na atualidade (2a ed.). Rio de Janeiro, RJ: Civilização Brasileira.

Bocchi, J. C., \& Campos, É. B. V. (2018). Morte, narcisismo e invisibilidade nos quadros limítrofes: um estudo clínico. Natureza Humana, 20(1), 115-133.

Campos, E. B. V. (2014). Limites da representação na metapsicologia freudiana. São Paulo, SP: Edusp.

Campos, E. B. V.(2016). Uma perspectiva psicanalítica sobre as depressões na atualidade. Estudos Interdisciplinares em Psicologia, 7(2), 22-44.

Costa, J. F. (1988). Violência e psicanálise (3a ed.). Rio de Janeiro, RJ: Graal.

Costa, J. F. (2005). O vestígio e a aura: corpo e consumismo na moral do espetáculo. Rio de Janeiro, RJ: Garamond.

Costa, J. F. (2007). O risco de cada um: e outros ensaios de psicanálise e cultura. Rio de Janeiro, RJ: Garamond.

Dunker, C. I. L. (2015). Mal-estar, sofrimento e sintoma: uma psicopatologia do Brasil entre muros. São Paulo, SP: Boitempo.

Figueiredo, L. C., \& Coelho Junior, N. E. (2018). Adoecimentos psíquicos e estratégias de cura: matrizes e modelos em psicanálise. São Paulo, SP: Blucher.

Freud, S. (1995). Projeto de Psicologia (O. F. Gabby Junior, Trad.). Rio de Janeiro, RJ: Imago. (Trabalho original publicado em 1895).

Freud, S. (2010). Introdução ao narcisismo. In Obras completas (P. C. de Souza, Trad., Vol. 12, pp. 13-50). São Paulo, SP: Companhia das Letras. (Trabalho original publicado em 1914).

Freud, S. (2010). Luto e melancolia. In Obras completas (P. C. de Souza, Trad., Vol. 12, pp. 170-194). São Paulo, SP: Companhia das Letras. (Trabalho original publicado em 1917).

Freud, S. (2010). Além do princípio do prazer. In Obras completas (P. C. de Souza, Trad., Vol. 14, pp. 161-239). São Paulo, SP: Companhia das Letras. (Trabalho original publicado em 1920).
Freud, S. (2011). Psicologia das massas e análise do eu. In Obras completas (P. C. de Souza, Trad., Vol. 15, pp. 13-113). São Paulo, SP: Companhia das Letras. (Trabalho original publicado em 1921).

Freud. S. (2011). Neurose e Psicose. In Obras completas (P. C. de Souza, Trad., Vol. 16, pp. 176-183). São Paulo, SP: Companhia das Letras. (Trabalho original publicado em 1924).

Freud, S. (2014). Inibição, sintoma e angústia. In Obras completas (P. C. de Souza, Trad., Vol. 17, pp. 13-123). São Paulo, SP: Companhia das Letras. (Trabalho original publicado em 1926).

Freud, S. (2014). O futuro de uma ilusão. In Obras completas (P. C. de Souza, trad., Vol. 17, pp. 231-301). São Paulo, SP: Companhia das Letras. (Trabalho original publicado em 1927).

Freud, S. (2010). O mal-estar na civilização. In Obras completas (P. C. de Souza, trad., Vol. 18, pp. 13-122). São Paulo, SP: Companhia das Letras. (Trabalho original publicado em 1930).

Fuks, B. B. (2003). Freud e a cultura. Rio de Janeiro, RJ: Zahar.

Garcia, C. A., \& Coutinho, L. G. (2004). Os novos rumos do individualismo e o desamparo do sujeito contemporâneo. Psychê: Revista de Psicanálise, 13(8), 124-140.

Green, A. (1988). Narcisismo de vida, narcisismo de morte. São Paulo, SP: Escuta.

Menezes, L. S. (2012). Desamparo (2a ed.). São Paulo, SP: Casa do Psicólogo.

Pereira, M. C. (2008). Pânico e desamparo: um estudo psicanalítico (2a ed.). São Paulo, SP: Escuta.

Rocha, Z. (1999). Desamparo e metapsicologia: para situar o conceito de desamparo no contexto da metapsicologia freudiana. Sintese, 26(86), 331-346.

Rocha, Z. (2000). Os destinos da angústia na psicanálise freudiana. São Paulo, SP: Escuta.

Schneider, M. (1997). A proximidade em Lévinas e o nebensmench freudiano. Cadernos de Subjetividade, 5(1), 71-90.

Winnicott, D. W. (1989). O medo do colapso. In D. Winnicott, Explorações psicanaliticas (pp. 70-76). Porto Alegre, RS: Artmed. (Trabalho original publicado em 1974).

Recebido: 05/02/2019

Revisado: 02/07/2020

Aprovado: 14/06/2021 